\title{
Fetal Oropharyngeal and Neck Tumors: Determination of the Need for Ex-Utero Intrapartum Treatment Procedure
}

\author{
Fatma Tuncay Özgünen ${ }^{1}$, Ümran Küçükgöz Güleç ${ }^{1}$ İ́smail Cüneyt Evrüke ${ }^{1}$, Süleyman Cansun Demir ${ }^{1}$, \\ Selim Büyükkurt ${ }^{1}$, Hacer Yapıcıoğlu ${ }^{2}$, Serdar İskit ${ }^{3}$
}

\begin{abstract}
${ }^{1}$ Department of Obstetrics and Gynecology, Çukurova University Faculty of Medicine, Adana, Turkey
${ }^{2}$ Department of Pediatrics Neonatalogy Unit, Çukurova University Faculty of Medicine, Adana, Turkey ${ }^{3}$ Department of Pediatric Surgery, Çukurova University Faculty of Medicine, Adana, Turkey
\end{abstract}

Background: The aim of this study was to assess the ex-utero intrapartum therapy (EXIT) applied to 3 of the 7 cases with oropharyngeal or neck masses and review the indicators of the need for an EXIT procedure.

Case Report: Prenatal presentation, size and localization of the masses, existence of fetal hydrops and associated findings such as polyhydramnios, intraoperative managements, complications, and maternal and neonatal outcomes were evaluated through a retrospective analysis. Four cases had neck masses and three cases had oropharyngeal masses. Prenatal sonography was used as the main diagnostic tool for all patients. The median gestational age was 34.5 weeks at the time of diagnosis and 36 weeks at delivery. Polyhydramnios was observed in three of the seven cases and they were delivered prematurely. Interventions such as en- dotracheal intubation or tracheostomy were performed to provide patency of the airway during delivery by the EXIT procedure in three cases. Hemangioma was found in two cases, teratoma in two cases, lymphangioma in two cases and hamartoma in one case following pathological examination of the masses.

Conclusion: The localization of mass, its characteristics, invasion (if it exists), and relation to the airway are the main factors used to determine the need for EXIT. The presence of polyhydramnios may be an important indicator to predict both the need for EXIT and fetal outcomes.

Keywords: Ex-utero intrapartum therapy (EXIT), fetal oropharyngeal tumors, fetal neck tumors, polyhydramnios, ultrasonography
Oropharyngeal and neck tumors are rarely seen in fetal life. The lesions located in the area involve cystic hygroma, teratoma, ranula, epulis, hemangioma, congenital goiter, solid thyroid tumor, thyroid cyst or thyroglossal duct cyst, branchial cleft cyst, neuroblastoma and hamartoma. The most common types are cervical teratoma and cystic hygroma (1). These tumors have the potential to obstruct the airway, which can be life threatening, and endotracheal intubation can be difficult or impossible due to anatomic distortion.
The aim of the ex-utero intrapartum therapy (EXIT) procedure is to maintain the newborn's airway open during placental circulation after the partial delivery of a fetus, and, in this way, to protect the fetus from hypoxia until providing an open airway (2). As fetoplacental circulation continues, endotracheal intubation is implemented for opening the airway of the fetus. If this is not possible, other interventions such as bronchoscopy or tracheostomy and excision of the mass can be applied (1-3). However, the EXIT procedure is not a treat-

This study was presented at the $20^{\text {th }}$ World Congress on Ultrasound in Obstetrics and Gynecology, 10-14 October 2010, Prague, Czech Republic.

Address for Correspondence: Dr. Ümran Küçükgöz Güleç, Department of Obstetrics and Gynecology, Çukurova University Faculty of Medicine, Adana, Turkey Phone: +905334616293 e-mail: ukucukgoz@yahoo.com

Received: 13.12.2013 Accepted: 04.08.2014 • DOI: 10.5152/balkanmedj.2015.150096

Available at www.balkanmedicaljournal.org 
TABLE 1. Descriptive data, procedure characteristics and outcomes of the cases

\begin{tabular}{|c|c|c|c|c|c|c|c|c|c|c|c|c|}
\hline $\begin{array}{r}1 \\
\text { Case }\end{array}$ & $\begin{array}{l}\text { Maternal } \\
\text { age }\end{array}$ & $\begin{array}{l}\text { Gestational } \\
\text { age at } \\
\text { diagnosis }\end{array}$ & $\begin{array}{c}\text { Gestational } \\
\text { age } \\
\text { at birth }\end{array}$ & $\begin{array}{l}\text { Ultrasonog- } \\
\text { raphic } \\
\text { findings }\end{array}$ & $\begin{array}{l}\text { Additional } \\
\text { evaluation } \\
\text { methods }\end{array}$ & $\begin{array}{l}\text { Preoperative } \\
\text { interventions } \\
\text { and applications }\end{array}$ & $\begin{array}{l}\text { Birth } \\
\text { weight } \\
\text { s (g) }\end{array}$ & $\begin{array}{l}\text { Duratio } \\
\text { of } \\
\text { EXIT }\end{array}$ & Procedure & $\begin{array}{l}\text { Apgar } \\
\text { score } \\
\left(1^{\prime}-5^{\prime}\right)\end{array}$ & Status & $\begin{array}{c}\text { Pathological } \\
\text { diagnosis }\end{array}$ \\
\hline 1 & 23 & $381 / 7$ & 39 & $\begin{array}{l}\text { Oropharyngeal tumor size } \\
\text { of } 85 \times 88 \mathrm{~mm} \text {, including } \\
\text { solid and cystic components, } \\
\text { tongue protrusing from mouth, } \\
\text { color doppler ultrasonography } \\
\text { pattern involving high vascular } \\
\text { composition and low resistance }\end{array}$ & - & - & 3380 & - & - & $7-9$ & Exitus & Hemangioma \\
\hline 2 & 21 & 34 & 34 & $\begin{array}{l}\text { Oropharyngeal tumor approximate } \\
\text { size of } 43 \times 21 \times 18 \mathrm{~mm} \text {, including } \\
\text { solid and cystic components, } \\
\text { polyhydramnios }\end{array}$ & & - & 1908 & $11^{\prime}$ & Tracheostomy & y $3-7$ & Exitus & Hemangioma \\
\hline 3 & 32 & $261 / 7$ & $332 / 7$ & $\begin{array}{l}\text { Oropharyngeal tumor, } \\
\text { approximately size of } \\
45 \times 24 \times 35 \mathrm{~mm} \text {, including } \\
\text { solid and cystic components, } \\
\text { polyhydramnios }\end{array}$ & $\begin{array}{l}\text { MRI, } \\
\text { fetal echo }\end{array}$ & $\begin{array}{l}\text { Amniodrainage, } \\
\text { tocolysis, } \\
\text { betamethasone }\end{array}$ & 2500 & 4 ' & $\begin{array}{l}\text { Endotracheal } \\
\text { intubation }\end{array}$ & $4-7$ & Exitus & Teratoma \\
\hline 4 & 28 & $383 / 7$ & $383 / 7$ & $\begin{array}{l}\text { The mass size of } 41 \times 61 \times 70 \mathrm{~mm} \text {, } \\
\text { including cystic component but } \\
\text { predominantly solid in neck. }\end{array}$ & , & - & 3100 & 6 & $\begin{array}{l}\text { Endotracheal } \\
\text { intubation }\end{array}$ & $8-9$ & Exitus & Teratoma \\
\hline 5 & 31 & $385 / 7$ & 39 & $\begin{array}{l}\text { Cystic mass size of approximately } \\
98 \times 41 \times 20 \mathrm{~mm} \text { in neck, extending } \\
\text { to bilateral submandibular area fro } \\
\text { midline of neck. }\end{array}$ & $\begin{array}{l}\text { ly - } \\
\text { ig } \\
\text { rom }\end{array}$ & - & 3300 & - & - & & $\begin{array}{l}\text { Alive and } \\
\text { healthy }\end{array}$ & Lymphangiomatosis \\
\hline 6 & 24 & $383 / 7$ & 39 & $\begin{array}{l}\text { Cystic mass size of } 67 \times 51 \times 40 \\
\text { mm in neck. }\end{array}$ & MRI & - & 2900 & - & - & $6-9$ & $\begin{array}{l}\text { Alive and } \\
\text { healthy }\end{array}$ & Lymphangiomatosis \\
\hline 7 & 32 & $281 / 7$ & 30 & $\begin{array}{l}\text { Predominantly solid mass size } \\
\text { of } 95 \times 63 \times 42 \mathrm{~cm} \text { in neck, } \\
\text { polyhydramnios, hydrops }\end{array}$ & MRI & Amniodrainage & 2720 & - & - & & $\begin{array}{l}\text { Intrauterine } \\
\text { loss }\end{array}$ & Hamartoma \\
\hline
\end{tabular}

EXIT: ex-utero intrapartum therapy; MRI: magnetic resonance imaging

ment without complications (4). In particular, insufficient equipment and unqualified staff may not only cause a poor fetal prognosis but also maternal complications. There are a few studies in the literature regarding which patients should receive the EXIT procedure (3-5). The aim of this study was to share our experiences on the antenatal and perinatal evaluation methods to determine the need for the EXIT procedure.

\section{CASE PRESENTATION}

Between January 2007 and September 2012, seven cases with oropharyngeal and neck masses were evaluated considering the EXIT procedure in our tertiary hospital. All parents had been informed about the EXIT procedure, difficulties and outcomes of the procedure. Informed consents were obtained. Demographic data, gestational age at time of diagnosis, gestational age at delivery, associated anomalies, pre-operative findings and applied procedures, neonatal and maternal out- comes, and histopathological diagnoses were reviewed. The cases were consulted with a neonatologist and pediatric surgeon regarding the need for EXIT. The cases were managed by a team including a perinatologist (FTO), a neonatologist (HY), a pediatric surgeon (SI), an otolaryngologist and an obstetric anesthesiologist. The data were obtained through the records of the patients. Ultrasonographic evaluation was conducted by the perinatologists (FTO, CE, and CD).

Seven cases with oropharyngeal and neck masses (three oropharyngeal and four neck masses) were evaluated for this study. All patients were referred to our clinic with fetal head-neck mass diagnosis and their regular antenatal followups were not performed in our clinic. We used two and threedimensional ultrasonography for diagnosis of the mass and magnetic resonance imaging (MRI) was used in addition to ultrasound to confirm the mass diagnosis in three patients. Characteristics of the patients are presented in Table 1 and the characteristics of the mass and photographs are presented in Figure 1-7. Polyhydramnios was the initial symptom in three 

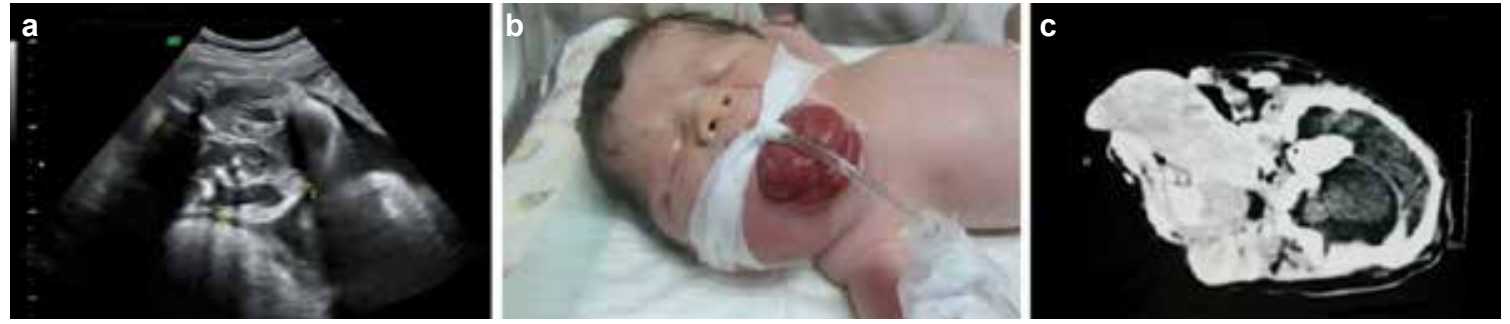

FIG. 1. a-c. Oropharygeal mass protruding from mount (a). Postnatal apperance of vascular mass (b). Postnatal computorized tomografic apperance of the mass (c).
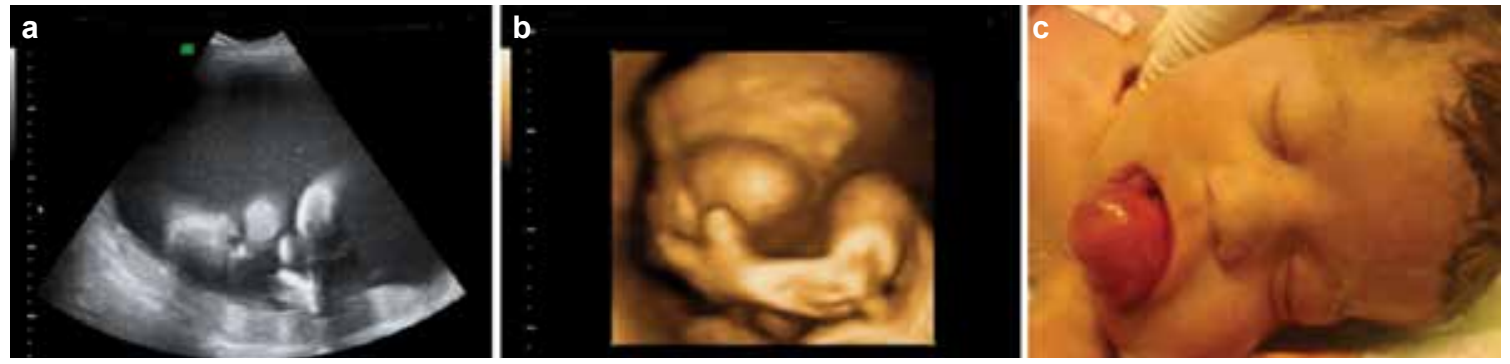
FIG. 2. a-c. Polyhydramniosis and
protruding mass from mouth (c).
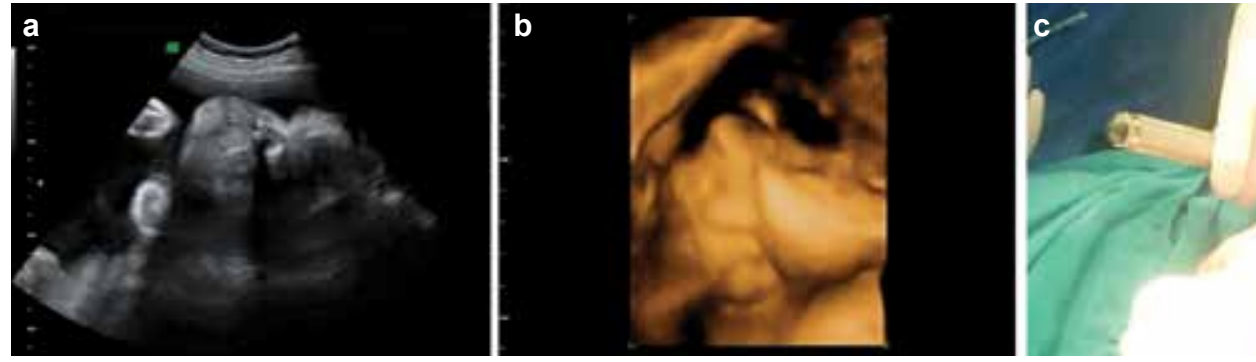

(b). Postnatal apperance of the

(a), 3D sonographic apperance of the mass

FIG. 3. a-c. Polyhydramniosis and fetal oropharyngeal solid-mass (a). 3D sonographic apperance of the mass (b). Endotracheal intubation by EXIT procedure (c).

cases. One of them had hydrops and a large tumor in the neck and died in utero in the $30^{\text {th }}$ week of gestation (case 7). For three of the remaining six patients, we performed the EXIT procedure including two endotracheal intubations and one tracheostomy. On the other hand, for the other three patients, there was no need for the EXIT procedure because their airway passage was not obstructed.

No complications or over-bleeding requiring blood transfusion were observed in mothers. Six infants were admitted to the Newborn Intensive Care Unit. Unfortunately, two infants with hemangioma died due to bleeding (case 1 and 2) and two cases with teratoma died due to respiratory distress syndrome and pulmonary hypoplasia (case 3 and 4, respectively). The remaining two cases with lymphangioma are alive. One of the living infants recovered following surgery, whereas the other one was treated by the injection of sclerosing substance. Two cases had hemangioma, two had lymphangioma, two had teratoma, and one had hamartoma.

\section{DISCUSSION}

Fetal airway obstruction can be the result of not only an intrinsic lesion in the larynx or trachea, such as congenital high airway obstruction syndrome, but also oropharyngeal or neck masses with external compression (1-3). Airway obstruction at delivery can cause high perinatal mortality and morbidity. Thus, it is vital to ensure airway opening. The EXIT procedure should be considered if there is a concern associated with neonatal airway compromise or cardiorespiratory instability (3-5).

The EXIT procedure provides adequate time for placental bypass and includes life-saving procedures such as laryngoscopy, bronchoscopy, endotracheal intubation, tracheostomy, and the resection of neck masses (6). Prenatal diagnosis of fetal neck and oropharyngeal masses is generally performed using high-resolution ultrasonography. Identification of the mass during the antenatal period facilitates planning the delivery and EXIT procedure for each case. Accurate prenatal diagnosis and determining of the necessity of EXIT proce- 

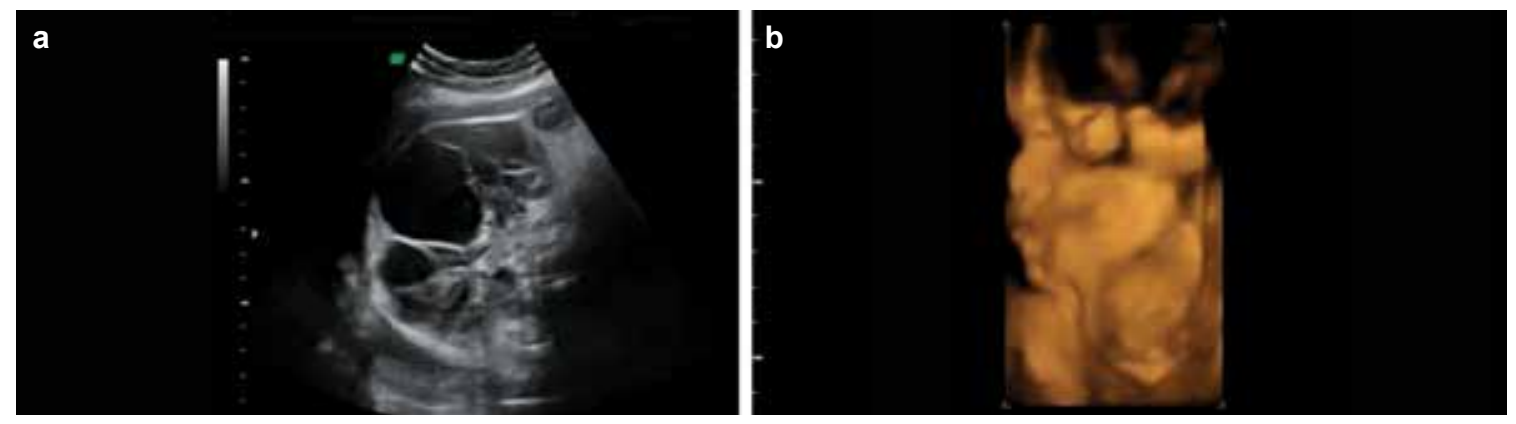

FIG. 4. a-b. Cystic and solid structure of the fetal neck mass (a). 3D sonographic apperance of the mass (b).
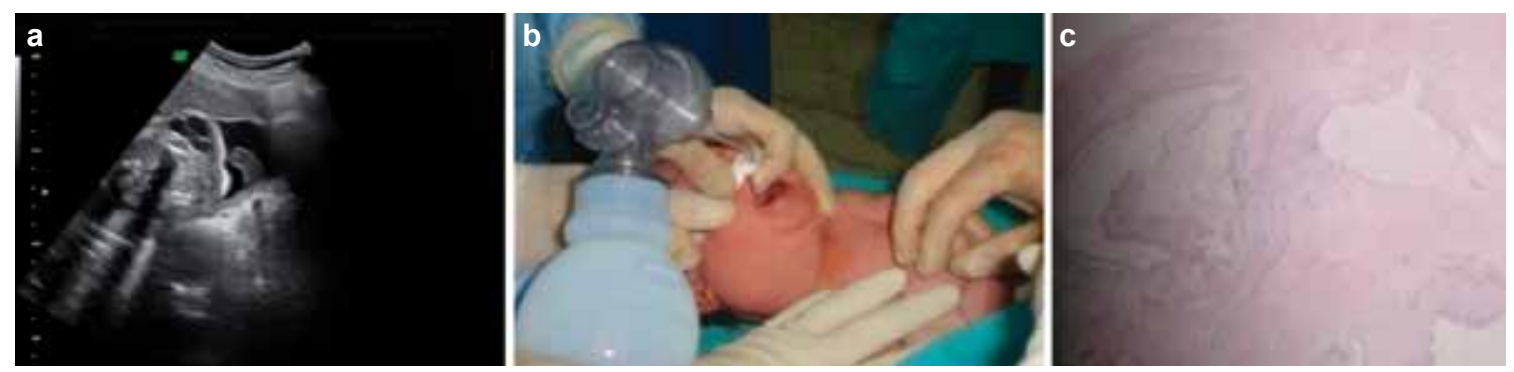

FIG. 5. a-c. Csytic mass with thin septa on fetal neck (a). Intrapartum fotograph of the cystic mass in neck (b). Histopathologic diagnosis was lymphangioma (c).
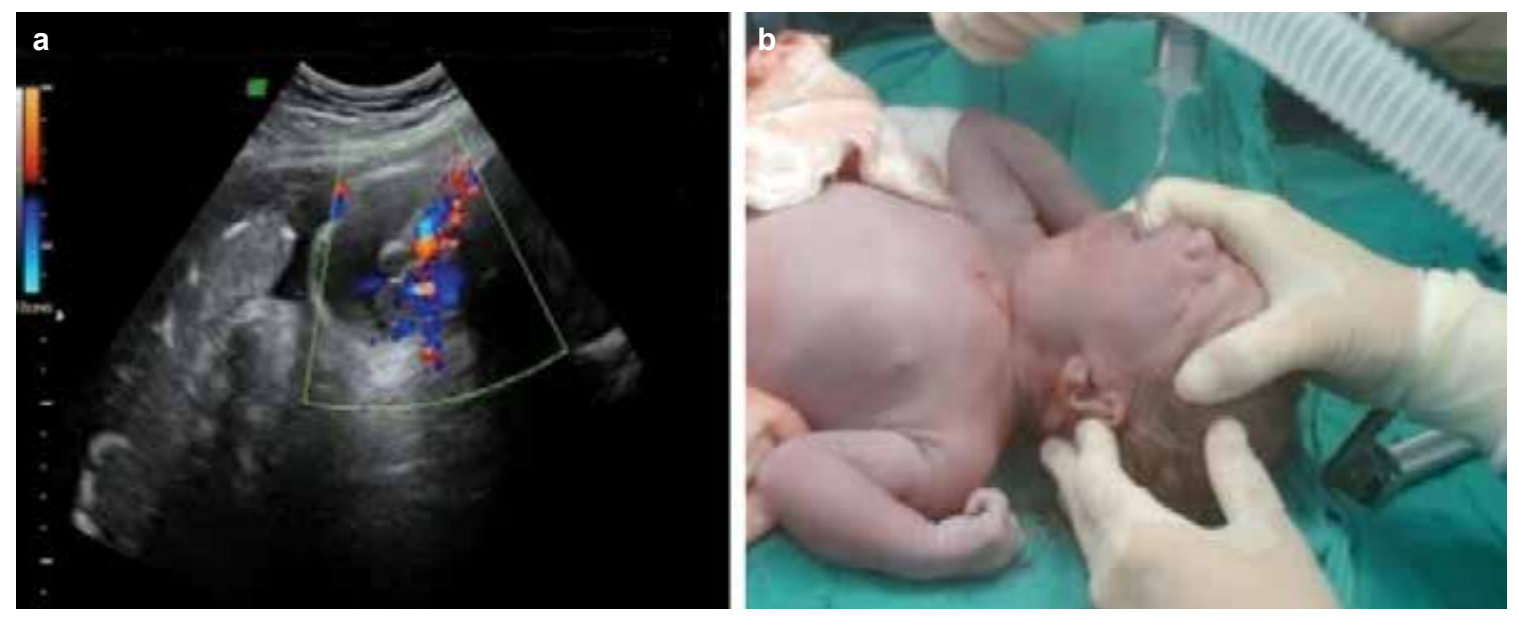

FIG. 6. a-b. Color doppler examination of the cystic mass in fetal neck (a). Endotracheal intubation was perform after the delivery of the fetus (b).
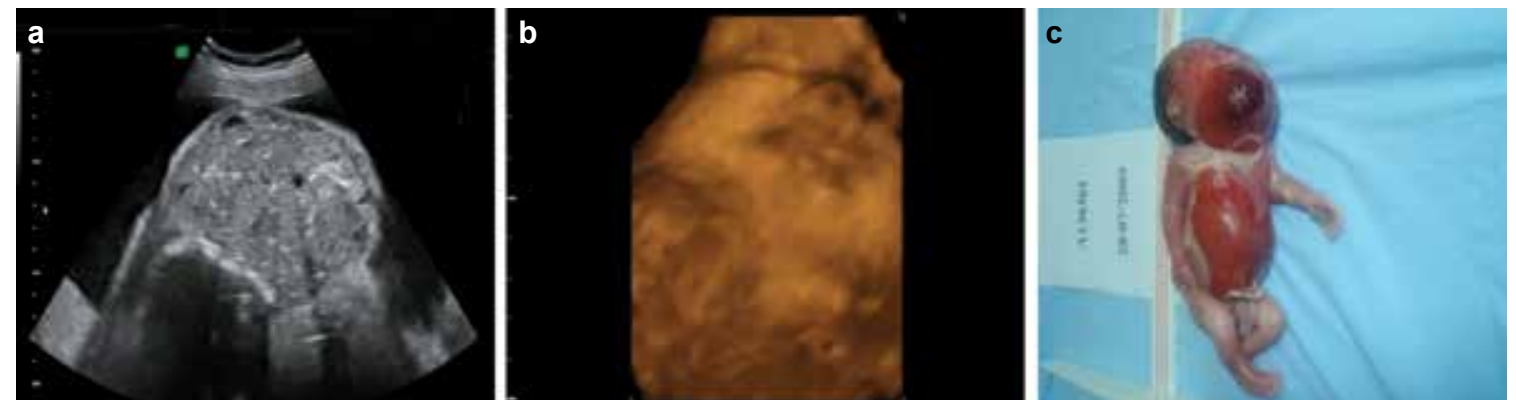

FIG. 7. a-c. Calcific solid mass in fetal neck region with polyhydramniosis (a). 3D sonographic apperance of the mass (b). This case had hidrops, polyhydramniosis and demised in-utero and diagnosis was hamartoma (c). 
dure are crucial for performing an effective EXIT procedure. Cystic hygroma (lymphangioma) is the most common fetal neck mass. It appears to be a cystic structure with multiple septa on ultrasound image, as in our two cases with lymphangioma. Fetal cervical teratoma occurs as a semisolid, semicystic mass mainly located to anterolateral in the fetal neck. In ultrasonographic evaluation, distinguishing the airway from the surrounding tissues and visualizing the obstruction and blockage may not always be easy. Ultrasound and MRI have been used together prenatally to determine the relationship between the fetal mass and the airway. In one case in which we used MRI, the quality of the imaging was negatively influenced because of the presence of polyhydramnios and MRI did not help us to obtain further opinion in terms of ultrasonographic imaging. The findings predicting cystic hygroma and airway patency in ultrasonograpic evaluation were confirmed using MRI in another two cases. Ultrasound is also an effective method for determining the calcification that may be useful to understand the mass nature and to recognize other associated anomalies such as hydrops or polyhydramnios. Hydrops can be caused by cardiac insufficiency associated with the obstruction in the giant tumors as well as arteriovenous shunting in the mass. Our last case had a giant neck mass and non-immune hydrops; this fetus died inutero. Polyhydramnios results from the obstruction caused by the growing mass within the fetal esophagus lumen and may cause preterm labor, as in our two cases. In these cases, endotracheal intubation or tracheostomy was performed using the EXIT procedure to provide the airway patency. For this reason, the existence of polyhydramnios may be an indirect indicator for airway obstruction; this finding is quite important, as in our cases. Kalanche et al. (5) suggested pulmonary Doppler ultrasonography to determine the necessity of the EXIT procedure and thus to avoid unnecessary EXIT processes. They reported that the airway of a fetus can be viewed by this technique.

A large series (12 cases) on EXIT procedure in fetal neck masses showed that EXIT can be performed safely for both the mother and child (7). There are a few cases reporting unsuccessful EXIT procedures (8). The most serious possible complication during the EXIT procedure is intraoperative hemorrhage, which can result from uterine atony or placental injury (4). A few cases of obstetric hemorrhage due to uterine relaxation or inadequate surgical hemostasis were reported (9). A uterine stapling device can be used for a bloodless hysterotomy. The empiric use of an oxytocin bolus followed by continuous infusion and uterine massage helps to restore uterine tone when the EXIT procedure is completed. Neonatal outcome depends on the primary diagnosis, the presence of airway distortion and the associated anomalies. The presence of polyhydramnios and hydrops in these cases can negatively affect prognosis. Long-term follow-up has not been sufficiently reported $(3,10)$. Parents should be informed about the difficulties and outcomes of the EXIT procedure in further detail. The localization and nature of the mass, the presence of polyhydramnios, and invasion degree (if exists) may be considered factors used to determine the need for the EXIT procedure. The presence of polyhydramnios should also be evaluated to predict prognosis.

\section{Ethics Committee Approval: N/A.}

Informed Consent: Written informed consent was obtained from the parents of the patients for the publication of this case report and the accompanying images.

Peer-review: Externally peer-reviewed.

Author contributions: Concept - .Ü.K.G., F.T.Ö.; Design Ü.K.G., F.T.Ö. İ.C.E.; Supervision - Ü.K.G, F.T.Ö.; Resource Ü.K.G., F.T.Ö., İ.C.E., S.C.D., S.B.; Materials - İ.C.E., S.B.; Data Collection \&/or Processing -.Ü.K.G., F.T.Ö., S.B.; Analysis \&/or Interpretation - Ü.K.G., F.T.Ö., H.Y.; Literature Search - Ü.K.G., F.T.Ö., S.B.; Writing.Ü.K.G., S.B., F.T.Ö.; Critical Reviews - Ü.K.G., H.Y.

Conflict of Interest: No conflict of interest was declared by the authors.

Financial Disclosure: The authors declared that this study has received no financial support.

\section{REFERENCES}

1. Hirose S, Harrison MR. The ex utero intrapartum treatment (EXIT) procedure. Semin Fetal Neonatal Med 2003;8:207-14. [CrossRef]

2. Marwan A, Crombleholme TM. The EXIT procedure: principles, pitfalls, and progress. Semin Pediatr Surg 2006;15:107-15. [CrossRef]

3. Olutoye OO, Olutoye OA. EXIT procedure for fetal neck masses. Curr Opin Pediatr 2012;24:386-93. [CrossRef]

4. Liechty KW. Ex-utero intrapartum therapy. Semin Fetal Neonatal Med 2010;15:34-9. [CrossRef]

5. Kalache KD, Masturzo B, Pierro A, Peebles D, Chitty LS. Prenatal evaluation of fetal neck masses in preparation for the EXIT procedure: The value of pulmonary Doppler Ultrasonography (PDU). Prenat Diagn 2001;21:308-10. [CrossRef]

6. Moldenhauer JS. Ex utero intrapartum therapy. Semin Pediatr Surg 2013;22:44-9. [CrossRef]

7. Lazar DA, Olutoye OO, Moise KJ Jr, Ivey RT, Johnson A, Ayres N, et al. Ex- utero intrapartum treatment procedure for giant neck massesfetal and maternal outcomes. J Ped Surg 2011;46:817-22. [CrossRef]

8. Awonuga AO, Bell J, Vallecilla D, Ray C, Yingling D, Helfgott A. Antenatal diagnosis and perinatal management of extremely giant fetal cervicopharyngeal teratoma resulting in impossible fetal intubation: a case report. Fetal Diagn Ther 2009; 25:340-2. [CrossRef]

9. Butwick A, Aleshi P, Yamout I. Obstetric hemorrhage during an exit procedure for severe fetal airway obstruction. J Can Anesth 2009;56:437-42. [CrossRef]

10. Abraham RJ, Sau A, Maxwell D. A review of the EXIT (Ex utero Intrapartum Treatment) procedure. J Obstet Gynaecol 2010;30:1-5. [CrossRef] 